\title{
Frequency, Prevalence, Interaction, and Gender Differences of Six Psychosocial Factors in Patients Presenting to a Psychiatric Emergency Service
}

\author{
James C. Patterson II, MD, PhD ${ }^{1}$ a , Ovais Khalid, MBBS², Sarah E. Wakefield, MD³ , Justin K. Liegmann, MD, Saima \\ Maqsood, MBBS ${ }^{5}$, Rajeev Srivastava, MBBS ${ }^{6}$, Elizabeth Allen, LCSW ${ }^{7}$ \\ 1 Department Chair and Professor, Department of Psychiatry and Behavioral Medicine, Louisiana State University Health Sciences Center, ${ }^{2}$ Eastern \\ Shore Psychological Services, ${ }^{3}$ Assistant Professor and Chair of Psychiatry, Texas Tech University Health Sciences Center, 4 Psychiatry, Ascension \\ Genesis Hospital, 5 Psychiatry, Peninsula Regional Health System, 6 Medical Director- Child and Adolescent Psychiatry, Gulfport Behavioral Health \\ System, ${ }^{7}$ Ochsner LSU Health Shreveport \\ Keywords: neglect, addiction, psychiatric emergency services, emergency room, psychosocial factors, psychiatry \\ https://doi.org/10.52965/001c.24445
}

\section{Health Psychology Research}

Vol. 9, Issue 1, 2021

\section{INTRODUCTION}

The psychiatric emergency service (PES) has become an increasingly utilized patient care approach over the past 50 years. Psychosocial factors play an important role in PES utilization and disposition of patients in this environment. PES utilization in our region has increased $450 \%$ in the past 18 years, while the population has changed $<1 \%$. Our objective was to determine the frequency and relationship between six psychosocial factors in our patients, in comparison to the general population.

\section{METHODS}

We completed a retrospective chart review of 160 patients selected at random who utilized the PES during 2009-2010. We looked for historical presence of a broken family, abuse or neglect, substance abuse, legal problems, violence, or incomplete education. We also looked at the relationship of these factors to race and gender.

\section{RESULTS}

$75 \%$ had three or more of the factors measured. In our population, substance abuse and broken family were most prevalent. Females had significantly more abuse or neglect as compared to males, while male subjects had significantly more substance abuse and legal issues than females. The presence of a broken family was strongly associated with abuse or neglect, while violence was associated with incomplete education and legal issues. The prevalence of these factors in our patients was higher than the general population.

\section{CONCLUSION}

The average patient presenting to the PES has multiple major psychosocial problems at higher frequencies than the general population. Understanding the relationship between multiple psychosocial factors and increasing PES utilization can direct us towards addressing the problems causing the increase in PES presentation. A planned future prospective study will examine the incidence of these psychosocial factors in patients presenting to the PES as compared to the general population.

\footnotetext{
a Corresponding author: James C. Patterson II, MD, PhD

Louisiana State University Health Sciences Center

1501 Kings Highway,

Shreveport, LA 71103318-675-6042 phone

318-675-6148 fax

jpatte@Isuhsc.edu
} 


\section{ABBREVIATIONS}

PES - Psychiatric Emergency Service

APA - American Psychiatric Association

SPSS - Statistical Package for the Social Sci-

ences

IBM - International Business Machines

ANOVA - Analysis of Variance

SAMHSA - Substance Abuse and Mental Health

Services Administration

\section{INTRODUCTION}

In 2002, the APA's Task Force published their report and recommendations for PES model programs. ${ }^{1}$ In this report, the typical PES was described as a "service under siege." It was noted that there had been "a massive increase in the volume and complexity of emergency presentations." The possible causes of this increase were reviewed briefly and include deinstitutionalization, managed care, substance abuse, and "other social ills." This report was of critical importance to Psychiatry and Emergency Medicine because as late as 1970, the field of Emergency Psychiatry was not recognized as a specific specialty for the majority of the United States. The report provided recommendations for crisis intervention and described models of care that gave providers a framework for dealing with patient care in the emergency environment.

Another study looked at mentally ill patients' utilization of emergency department (ED) services. ${ }^{2}$ This review demonstrates the nature and extent of the issues impacting hospitals nationwide and points out that the problem has grown so severe that EDs are now "boarding” patients with mental illness. In our own emergency room (ER), by necessity, we had to develop a 17-bed Psychiatric Crisis Unit to manage the increased influx of patients.

A literature search reveals that the earliest publication on the presence and use of the PES was in $1965 .^{3}$ Even in early articles on the use of the PES, the importance of social factors was noted as playing an important role. For example, Miller in 1968 noted that it was important to look at both the patient and their social environment together when evaluating patients in the emergency setting with psychiatric issues. ${ }^{4}$ With the rapid changes that have accrued in our society over the past 50 years, this appears to be playing a larger role in PES presentations.

The impetus for this study was the increasing numbers of patients admitted to the PES component of the Emergency Department of our university-based hospital. During the past 18 years, this number has increased by almost $450 \%$ (see Figure 1). This is in contrast to the change in the local population, which has decreased approximately $1 \%$ in the same time period.

With regard to the reasons for this disparate increase in PES presentations, we looked again to the APA Task Force's report $^{1}$ as well as the APA Resource Document ${ }^{2}$ for possible causes. Deinstitutionalization has been historically viewed as a major cause for increased PES presentations. Figure 2 shows the number of beds overtime at the state hospital

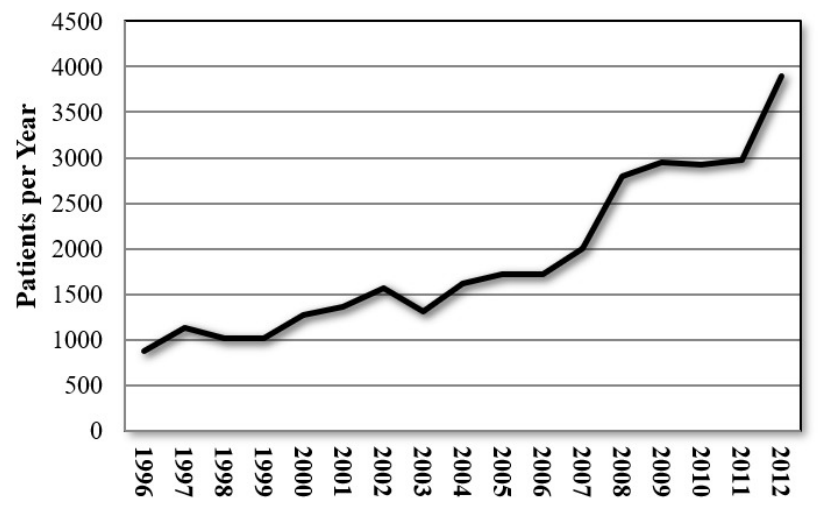

Figure 1. Annual new patient PES visits, 1996 2012.

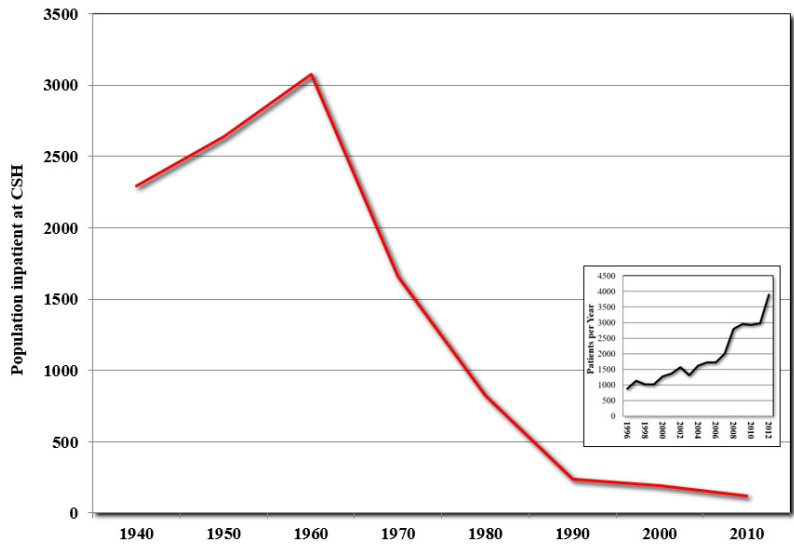

Figure 2. Deinstitutionalization at Central Louisiana State Hospital compared to PES influx (figure 1 inset for comparison).

Thanks to Robin Hogue, MD, for data from Central State Hospital.

that serves our area. From 1960 to 1990 , the number of beds dropped from over 3000 to $\sim 250$. From 1990 to 2012, there was a slow decline in the number of beds, but at a much lower pace. In essence, deinstitutionalization in our region was largely complete by 1990 . Inset onto this figure is the graph from Figure 1 at the appropriate location on the time axis. This demonstrates that the increase in patients presenting to the PES at our institution has been a more recent phenomenon. Furthermore, while this is based on observational data over the past decade, the vast majority of the patients who present to the PES at our institution are not in need of long-term commitment or institutionalization. Thus, the increase in PES utilization does not seem related to a major change in the number of beds in state mental health facilities.

Another listed contributor is "managed care." As a tertiary care center in Louisiana, we have always treated the indigent as well as others. Thus, managed care has not had much of an impact on care delivery over the past 15 years. In the past 20 years, the payor frequencies for our university-based hospital have changed in that we have a larger 
Table 1. Demographics.

\begin{tabular}{|l|l|l|l|}
\hline & \multicolumn{2}{|l|}{ Demographics } & \multicolumn{2}{l|}{ Females } \\
\hline & Total & Males & 82 \\
\hline $\mathrm{N}$ & 160 & 78 & 32 \\
\hline Race & \multicolumn{3}{|l|}{} \\
\hline African American & 60 & 28 & 0 \\
\hline Asian & 1 & 1 & 1 \\
\hline Hispanic & 2 & 1 & 49 \\
\hline Caucasian & $97^{*}$ & 48 & $37 \pm 13$ \\
\hline Age & $36 \pm 12$ & $35 \pm 10$ & 4 \\
\hline
\end{tabular}

Subjects were chosen in a retrospective chart review from a total of 250 patient records, and those with at least $90 \%$ complete information (psychosocial factors, suicidality, demographics) were chosen for evaluation. * - p=0.01 (two-tailed, Fisher's Exact Test).

frequency of patients with Medicaid instead of being selfpay or free care. However, patients with private health insurance make up only a small portion of our population (approximately 5 to $7 \%$ ). A previous report documents that the uninsured are high PES utilizers, ${ }^{5}$ but changes in Medicaid and disability have improved access to care for our previously self-pay patients. While there is a relationship, the increase in patient flow to our PES started long before changes in Medicaid. Thus, once again, this does not appear to be a major contributor.

The other items mentioned in the Task Force report are substance abuse and other "social ills." Psychosocial factors play an important role in psychiatry, and the biopsychosocial model of psychiatry attests to this importance. Therefore, one hypothesis for the increased rate of presentation of patients to the PES is due to the impact of negative influences from multiple major psychosocial factors. Our goals for this retrospective examination were to examine the frequency and inter-relatedness of six psychosocial factors in our patient population. The presence of an electronic medical record made this retrospective review straightforward, and data was collected on a subset of 160 patients seen in the PES setting during 2009-2010.

\section{METHODS}

\section{SUBJECTS}

This project was carried out at the Louisiana State University Health Sciences Center in Shreveport. It was approved by the Institutional Review Board before initiation. Waiver for consent was obtained due to the nature of the study. The electronic medical record was used to complete a retrospective chart review of a total of 250 subjects randomly chosen from all patients who presented to the PES during the time period 2009-2010. We also ensured that approximately equal numbers of male and female subjects were represented. From these, we excluded subjects that had more than one factor missing from the dataset, leaving $160 \mathrm{sub}$ jects. Table 1 lists the demographics for the subjects that were selected for this study.

\section{PROCEDURES}

The medical record for each subject was reviewed for documentation of the psychosocial factors listed in Table 2. These data were collected and analyzed using SPSS. Fisher's exact test was used to examine differences in the frequency of psychosocial factors between males and females. ANOVA was used to examine whether or not the presence of a specific factor was predictive of being associated with more than one factor by looking at the relationship with the number of factors in that patient. In this calculation, the number of factor components was corrected (n-1) for the absence of the one initial factor. Chi-squared analysis was used to look at relationships between individual factors as well as the relationship to race, suicidality, and to whether the patient was admitted to the inpatient unit from the PES. Comparison to national prevalence rates (where available) is reported in the discussion, but statistical examination of these comparisons was not feasible due to differences in data collection mechanisms.

\section{RESULTS}

This was a retrospective chart review of a total of $250 \mathrm{sub}$ jects randomly chosen from all patients who presented to the PES during the time period 2009-2010. Table 1 lists the demographics for the subjects that were selected for this study. Out of 78 males, 28 were African American, and 48 were Caucasians, with 1 Asian and 1 Hispanic subject, respectively. There were 82 female patients, including 32 African American, 49 Caucasian, and 1 Hispanic subject. There were significantly more Caucasians than AfricanAmerican patients in this dataset $(\mathrm{p}=0.01)$. The mean age range of male patients was $35+/-10$ years, and the mean age range of females was $37+/-13$ years respectively and was not significantly different.

Our initial analysis was focused on determining the frequency and distribution of psychosocial factors in our study population and then determining the relationships between psychosocial factors as well as race and gender. We also examined whether or not the patient was admitted and the presence of suicidality. Suicidal thoughts, plans, attempts, 
Table 2. Psychosocial Factors.

\begin{tabular}{|l|l|}
\hline Factors & Details \\
\hline $\begin{array}{l}\text { Substance } \\
\text { abuse }\end{array}$ & illicit drug or alcohol abuse or dependence, including prescription medications that can be abused \\
\hline Broken family & $\begin{array}{l}\text { Absence of a parent, raised by someone else other than parents, foster parents, divorced or separated parents, } \\
\text { step-parents }\end{array}$ \\
\hline $\begin{array}{l}\text { Legal } \\
\text { problems }\end{array}$ & $\begin{array}{l}\text { History of incarceration, jail, detention, probation, parole, or major legal problems that didn't lead to arrest (e.g., } \\
\text { police frequently called to the house) }\end{array}$ \\
\hline $\begin{array}{l}\text { Abuse or } \\
\text { neglect }\end{array}$ & Either adult or childhood abuse: sexual, physical, verbal/emotional abuse, or neglect \\
\hline $\begin{array}{l}\text { Violence } \\
\text { history }\end{array}$ & History of violent acts to others \\
\hline $\begin{array}{l}\text { Incomplete } \\
\text { education }\end{array}$ & High school dropout or equivalency certificate (indicates there were problems in education initially) \\
\hline
\end{tabular}

These were the factors evaluated in the study and the criteria used to determine whether or not a factor was present or not.

and gestures are common in the PES setting, thus important to study.

Table 2 lists the psychosocial factors that were examined as a part of this study, as well as the criteria for establishing the presence or absence of a psychosocial factor. Figure 3 shows the frequency of psychosocial factors in all subjects. The average number of factors per patient was 3.3.

Figure 4 shows the results from the frequency analysis of psychosocial factors in all subjects. Across the six psychosocial factors, substance abuse (78\%) and broken family (75\%) had the highest rates, and incomplete education had the lowest rate (32\% on average). This graph demonstrates that females had significantly more reported abuse or neglect than males $(\mathrm{p}<0.0001)$, and males had significantly more substance abuse $(p<0.0001)$ and legal issues $(p=0.01)$ than females. Males and females were not significantly different in the reported presence of a broken family, incomplete education, or violence.

Whereas Figure 4 shows the frequency of any given factor in a patient, Figure 5 shows the number of psychosocial factors per patient. In our patient population represented by this retrospective chart review, $75 \%$ had three or more psychosocial factors, and $47 \%$ had four or more factors.

Table 3 shows the relationship between psychosocial factors, race, suicidality, inpatient admission, and the number of factors present per patient. Importantly, there was not a significant relationship between the number of factors and admission to the inpatient service. Among the factors, the presence of a broken family was strongly associated with a reported history of abuse or neglect. The presence of violence was significantly related to reported incomplete education and legal problems, and legal problems were also related to substance abuse. Surprisingly, a history of violence was associated with less suicidality. Violent patients were also admitted more frequently than less violent patients. There were significant differences between races as well. As there were only two Hispanic patients and one Asian patient, these subjects were excluded from this analysis. In our patients, African-American patients were less numerous (60 African-American vs. 97 Caucasian), were admitted more frequently $(p=0.0251)$, and had more violence re-

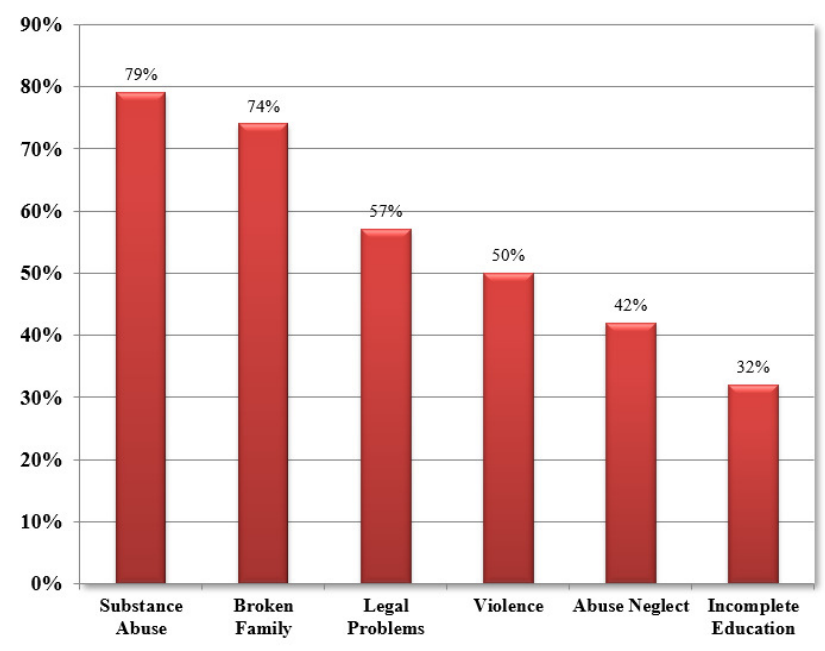

Figure 3. Frequency of psychosocial factors in all subjects.

ported $(\mathrm{p}=0.0006)$, whereas Caucasian patients had more suicidality ( $p=0.0003)$. Substance abuse was the only factor that was not associated with more frequent psychosocial factors - the presence of any other factor was predictive of the presence of more than one factor, with legal problems having the strongest association $(\mathrm{p}=0.0002)$.

\section{DISCUSSION}

This retrospective study looks at patients utilizing the PES and provides an overview of the frequency of six psychosocial factors, as well as the relationships between them, in addition to looking at the relationship to race, gender, and admission to the inpatient service. The main goal of this project was to examine the patient characteristics of those presenting to the PES to determine if there was anything that could account for the $450 \%$ increase in presentation rate. We demonstrate in this report that the profile of the average patient presenting to the PES is that of someone 
Table 3. Association between Factors.

\begin{tabular}{|c|c|c|c|c|c|c|c|}
\hline & Race & $\begin{array}{c}\text { Abuse or } \\
\text { Neglect }\end{array}$ & $\begin{array}{c}\text { Broken } \\
\text { Family }\end{array}$ & $\begin{array}{c}\text { Incomplete } \\
\text { Education }\end{array}$ & $\begin{array}{c}\text { Substance } \\
\text { Abuse }\end{array}$ & Violence & $\begin{array}{c}\text { Legal } \\
\text { Problems }\end{array}$ \\
\hline $\begin{array}{c}\text { Broken } \\
\text { Family }\end{array}$ & & $<0.0001$ & --- & & & & \\
\hline Violence & $0.0009^{*}$ & & & 0.009 & & -- & $<0.0001$ \\
\hline $\begin{array}{c}\text { Legal } \\
\text { Problems }\end{array}$ & & & & & 0.041 & $0.0044^{+}$ & \\
\hline Suicidality & $0.0003^{\#}$ & & & & & 0.001 & \\
\hline Admission & $0.0338^{*}$ & & & & & 0.004 & 0.0002 \\
\hline $\begin{array}{c}\text { Number of } \\
\text { factors }\end{array}$ & $<0.0001^{\#}$ & 0.01 & 0.0555 & 0.017 & & & 0 \\
\hline
\end{tabular}

Chi-square test was used to determine significance for all values except for Number of Factors, where ANOVA was used. * African-American > Caucasian, \# - Caucasian > AfricanAmerican, + - More Violent = Less Suicidality. As mentioned in the Methods, the calculation for the number of factors was corrected for the absence of one factor.

with multiple major psychosocial problems.

Louisiana has a large population at or near the poverty level and in lower socioeconomic brackets compared to the national average: $18.6 \%$ vs. $11.8 \%$, respectively. ${ }^{6}$ While the socioeconomic status of those subjects included in this manuscript was not examined, our hospital serves as a tertiary care center that has a large population of those without insurance or on Medicaid.

While all of these factors have been present to some degree in our society, it has only been in the past 50 years that many of them have been increasing in frequency in the United States. ${ }^{7}$ The APA's Task Force Report, ${ }^{1}$ as well as others, have documented the increased rates of PES utilization, and so it is important to examine the type, frequency, and relationships of psychosocial factors in those presenting to the PES. Each psychosocial factor we examined is discussed below in more detail.

\section{SUBSTANCE ABUSE}

For our research, we defined substance abuse as current or recent illicit drug or alcohol abuse or dependence, including prescription medications that can be abused. The overall rate of substance use disorders in our population was $79 \%$, with a significant difference between males (91\%) and females (66\%). This difference in rate is consistent with what is reported in national surveys. For comparison, the national prevalence of overall substance abuse, including alcohol, was $8.6 \%$ in 2010 , with rates of $12.2 \%$ in males and $5.8 \%$ in females. ${ }^{8}$ We also saw a significant relationship to legal problems, as one would expect from the use of illicit substances.

\section{BROKEN FAMILIES}

We defined this factor as being raised with the absence of a parent, raised by someone else other than parents, having foster parents, having divorced or separated parents, or having step-parents. In our patients, $74 \%$ were from broken families. This factor did not distinguish between severely broken families where there was abandonment and foster care vs. simple divorce and remarriage of parents. However,

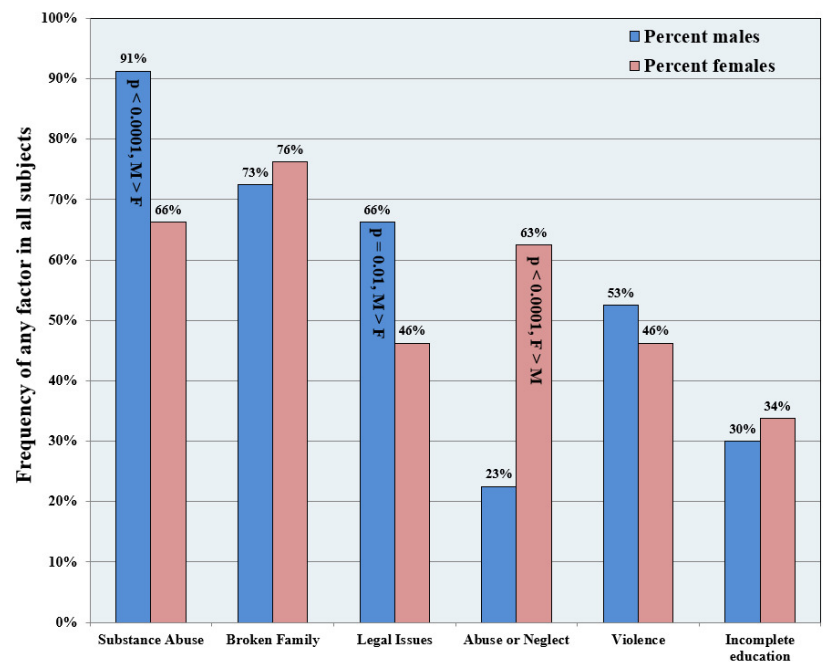

Figure 4. Frequency and comparison of psychosocial factors in males and females.

Fisher's exact test was used to determine significance.

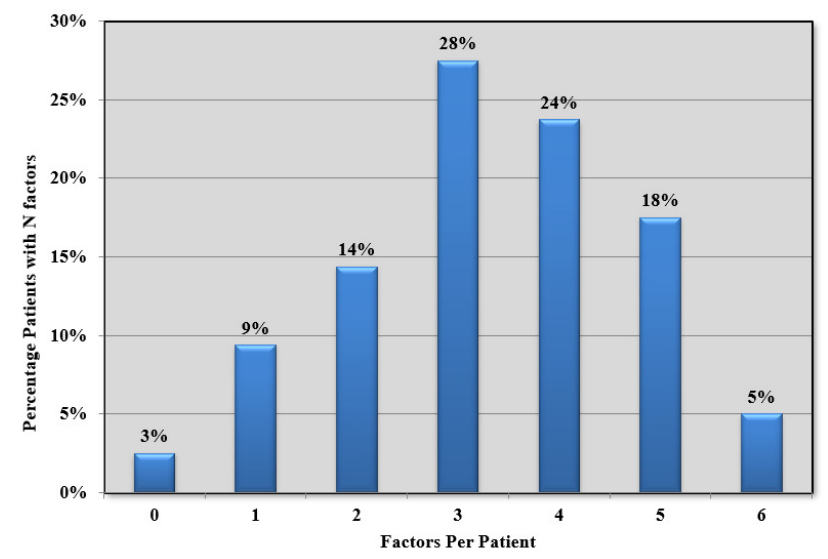

Figure 5. The number of psychosocial factors per patient. 
this is still higher than the current rate of broken families in the United States. The Pew Foundation published a report that documents that the rate in 2014 was $54 \%$, compared to $39 \%$ in $1980 .{ }^{9}$ For comparison, our study data was collected in 2009-2010. Thus there seems to be higher rates of patients presenting to our PES coming from broken families.

\section{LEGAL ISSUES}

In our study, we defined legal issues as having a history of incarceration, jail, detention, probation, parole, or major legal problems that didn't lead to arrest (e.g., police frequently called to the house). Legal problems were present in $57 \%$ of the patients reviewed for this study overall, but there was a significantly higher rate in males (66\%) vs. females (46\%). As mentioned previously, legal problems were significantly correlated with substance abuse, and they were also strongly and significantly associated with a history of violence (See Table 3).

As our definition of legal issues was a bit broad, it is difficult to compare directly to a similar value reported in the literature. In addition, the rates of imprisonment in the United States have changed over the years. However, there are some statistics worth looking at for a general idea of these issues. For example, the lifetime likelihood for imprisonment in males is currently at $11.1 \%$ and $1.8 \%$ for females. ${ }^{10}$ Thus, there seems to be higher rates of legal issues in patients presenting to our PES.

\section{ABUSE AND NEGLECT}

The connection between childhood abuse or neglect and later morbidity and mortality is well-known and documented. For our study, we defined this factor as either childhood or adult abuse and included all types (sexual, physical, verbal, emotional), as well as neglect. This connection is further supported by the research presented here. In our research, the overall rate of abuse in patients presenting to the PES was $42 \%$, but there was a significant difference between females (63\%) and males (23\%). We found a strong relationship between a history of abuse/neglect and being from a broken family $(\mathrm{p}<0.0001)$ consistent with previous results. ${ }^{11}$ For comparison, a review done in 2015 looking at worldwide rates of abuse between 1980 and 2008 found that child maltreatment impacts an estimated $12.7 \%$ of children through sexual abuse (affecting over twice as many girls compared to boys $18 \%$ vs. $7.6 \%), 22.6 \%$ through physical abuse, 36.3 through emotional abuse, 16.3 through physical neglect, and 18.4 through emotional neglect. ${ }^{12}$ While our study did not differentiate between different types of abuse and neglect, and the overall rate seems higher than that found worldwide.

\section{VIOLENCE HISTORY}

We defined this factor as the presence of a history of carrying out violent acts to others. This included physical altercations, domestic violence situations, fights using weapons, or any type of conflict beyond verbal. This did not include military conflict. We found that $49 \%$ of the patients in our review had a history of violence (53\% in males, $46 \%$ in fe- males). There were significantly higher rates of violence in African-American patients than in Caucasian patients, and violence was significantly associated with legal problems as well as having an incomplete education. In our chart review, violence was the only psychosocial factor predictive of admission to inpatient hospitalization and was negatively correlated to suicidality.

Again, due to how we defined violence in our population, there is not a good comparator. Sumner et al. reported in 2015 on prevalence rates for a broad array of different types of violence, but not a single global overall rate. ${ }^{13}$ They also point out that a history of experiencing violence as a child is associated with being violent as an adult and that violent acts are often under-report; thus, accurate data is wanting.

\section{INCOMPLETE EDUCATION}

Incomplete Education was evaluated in this review by determining whether a patient had dropped of school or had problems in school such that their education was interrupted, and they later obtained an equivalency certificate. The latter was included as it was frequently noted in inpatient records who presented to the PES. In our study, we found that $32 \%$ of patients had incomplete or interrupted education. This was significantly correlated with a history of violence.

High school drop-out rates vary by state. Louisiana data is available from the National Center for Education Statistics. For 2010, the percentage of individuals that were 25 years of age and older that had not completed high school was $18.2 \%{ }^{14}$ This report does not distinguish between a high school diploma or an equivalency certificate, however.

\section{OVERALL}

There has been some research done on various psychosocial factors and their relationship to PES utilization. ${ }^{15-19}$ Previous reports (reviewed in Arnow ${ }^{15}$ ) demonstrate a strong connection between childhood abuse and PES utilization, and one noteworthy study ${ }^{16}$ examined female patients in the PES and found that childhood sexual abuse was the most powerful predictor of later morbidity.

The factors that we picked to examine in this retrospective study were chosen based on empiric observation in our PES over several years, with respect to the extant literature on these factors. Drug and alcohol abuse/dependence in parents has been associated with abuse/neglect of children. ${ }^{17}$ Children who are the victims of abuse have a higher risk as adults of multiple issues including mood and anxiety disorders, ${ }^{15}$ psychosis, ${ }^{16}$ violence, ${ }^{20}$ substance abuse, ${ }^{15,21}$ legal problems, ${ }^{22}$ and abuse/neglect of their own children. ${ }^{16}$ Child abuse is more common in broken families ${ }^{21}$; children born into non-nuclear families are more likely to have non-nuclear families. ${ }^{23}$ Education problems are also more likely if there is childhood abuse. ${ }^{24}$ The connections between substance abuse and violence ${ }^{20,25}$ as well as legal problems ${ }^{26}$ are also documented in the literature.

Substance abuse was common in our patient population, as described in the results, and consistent with previous studies. ${ }^{15,16,18,27}$ The numbers in our study were higher than previous reports, but we included patients who had a 
history of recent abuse as well as those with current abuse and positive drug screens or alcohol levels. Perhaps because it was so prevalent in our population in both genders, we found only a significant relationship with legal problems in the Chi-squared analysis, and this was more frequent in males than females. The connection between substance abuse and both violence as well as legal problems was stronger in males than females.

One of the most interesting and unexpected results was that the presence of anyone factor (save for substance abuse) was predictive of the presence of another factor. This is internally consistent as we demonstrate that the majority of patients had three or more of the psychosocial factors present. Thus, it appears that these problems tend to cluster, at least in patients that present to the PES. Other than substance abuse, the next most prevalent factor was being from a broken family. This is turn, had a strong correlation to abuse and/or neglect ( $\mathrm{p}<0.0001)$.

While all these factors were highly prevalent, they did not necessarily lead to inpatient admission. A previous study reviewed patient characteristics of those presenting to a PES and found that the most important factor was related to psychiatric illness (e.g., underlying psychotic disorder) and that psychosocial factors played a secondary role. ${ }^{28}$ Our study does not examine diagnosis but is consistent with this previous report. In our study, only one psychosocial factor (violence) was predictive of admission.

\section{LIMITATIONS}

There are several limitations of this study that need to be pointed out. First, a retrospective chart review is limited to what data has been entered into the patient's medical record. This problem is variable depending upon the completeness of the history gathered at the time of the patient's evaluation, and there are many elements that contribute to the quality (or lack thereof) of this historical information. We addressed this problem to the extent possible by selecting patients with more complete medical records from the initial randomly selected pool, such that that the majority of patients had a complete dataset with regard to the six factors examined.

Importantly, the six psychosocial factors were categorical, such that the input data was Boolean - yes or no. There was no qualitative scalar response, as it proved difficult to establish with reasonable certainty the nature, extent, and severity of certain factors in many patients. Thus someone who has a diagnosis of occasional marijuana abuse would be "yes," as would someone with severe methamphetamine or polysubstance dependence. Similarly, someone who was acutely intoxicated on alcohol on one occasion would also be positively classified, as would someone with a thirty-year history of alcohol dependence. This was true not just for substances but, for example, abuse/neglect.

Another major limitation is that, while we think the fre- quency of psychosocial factors in this population are related to the increased number of patients presenting to the PES, we have no data from 20 years ago (before the increase) demonstrating that the frequency of factors than was less in patients coming into the emergency setting. We believe that the frequency of these factors was less in the general population in the distant past, but it is not accurate to state that this is true in the population from which our patients are drawn.

We chose not to examine employment status for a number of reasons, although this is an important social factor. A significant percentage of patients that we treat are on disability. Furthermore, some of these work part-time jobs and/or work in jobs that are not being reported as social security income (e.g., mowing yards). In this retrospective evaluation, it proved to be difficult to establish the employment status with any certainty in a significant percentage of the subjects.

Lastly, a very important psychosocial factor is homelessness. An anecdotal estimate of homelessness in our patients would be approximately $30 \%$. At the time this study was done, we were not tracking homelessness. It is our intent to address this in a future study.

\section{CONCLUSION}

Of the patients included in this retrospective study, 97\% had at least one of the six psychosocial problems examined, and the majority of these patients had three or more psychosocial factors, with an average of 3.3 factors per patient. The frequency and severity of these psychosocial factors are possibly related to the $>450 \%$ increase in patients seen in our PES over the past 18 years. However, it is unknown what the frequency of these factors was in patients presenting to the PES previous to this time period. A future proposed prospective study will examine the incidence of these psychosocial factors in patients presenting to the PES as compared to the general population.

\section{FUNDING}

Institutional/internal/departmental - no outside funding used.

\section{CREDITS}

Thanks to Robin Hogue, MD, for data on Central Louisiana State Hospital bed numbers for Figure 2.

\section{DISCLOSURES AND CONFLICTS OF INTERESTS}

None for any author.

Submitted: May 01, 2021 EST, Accepted: May 21, 2021 EST 


\section{REFERENCES}

1. Allen MH, Forster P, Zealburg J, et al. Report and Recommendations Regarding Psychiatric Emergency and Crisis Services - A Review and Model Program Descriptions. Published online August 2004.

2. Nordstrom K, Berlin JS, Siris S. Boarding of Mentally Ill Patients in Emergency Departments: American Psychiatric Association Resource Document. West J Emerg Med. 2019;20(5):690-695. do i:10.5811/westjem.2019.6.42422

3. Chafetz ME. The Effect of a Psychiatric Emergency Service on Motivation for Psychiatric Treatment. J Nerv Ment Dis. 1965;140(6):442-448. doi:10.1097/000 05053-196506000-00007

4. Miller WB. A Psychiatric Emergency Service and Some Treatment Concepts. Am J Psych. 1968;124(7):84-93. doi:10.1176/aip.124.7.924

5. Baillargeon J, Thomas CR, Williams B, et al. Medical Emergency Department Utilization Patterns Among Uninsured Patients with Psychiatric Disorders. Psychiatr Serv. 2008;59(7):808-811. doi:1 0.1176/ps.2008.59.7.808

6. Semega J, Kollar M, Creamer J, Mohanty A. United States Census Bureau Report: Income and Poverty in the United States: 2018. Accessed September 5, 2020. https://www.census.gov/library/publications/2019/de mo/p60-266.html

7. Bennett WJ. The Index of Leading Cultural Indicators - American Society at the End of the Twentieth Century. Random House; 2011.

8. SAMSHA Report: Results from the 2010 National Survey on Drug Use and Health: Summary of National Findings. Accessed September 5, 2020. https://www.s amhsa.gov/data/sites/default/files/NSDUHNationalFi ndingsResults2010-web/2k10ResultsRev/NSDUHresul tsRev2010.pdf

9. Pew Research Center - Social and Demographic Trends. Parenting in America: The American Family Today. Published online December 2015. Accessed September 5, 2020. https://www.pewsocialtrends.org/ 2015/12/17/1-the-american-family-today/

10. Criminal Justice Facts Report. Accessed September 5, 2020. https://www.sentencingproject.org/criminaljustice-facts

11. Oliver WJ, Kuhns LR, Pomeranz ES. Family Structure and Child Abuse. Clin Pediatr. 2006;45(2):111-118. doi:10.1177/00099228060450020 1
12. Stoltenborgh M, Bakermans-Kranenburg MJ, Alink LRA, van IJzendoorn MH. The Prevalence of Child Maltreatment across the Globe: Review of a Series of Meta-Analyses. Child Abuse Rev. 2015;24(1):37-50. doi:10.1002/car.2353

13. Sumner SA, Mercy JA, Dahlberg LL, Hillis SD, Klevens J, Houry D. Violence in the United States: Status, Challenges, and Opportunities. JAMA. 2015;314(5):478-488. doi:10.1001/jama.2015.8371

14. National Center for Education Statistics Report on Educational Attainment by State. Accessed September 5, 2020. https://nces.ed.gov/programs/digest/d12/tabl es/dt12 013.asp

15. Arnow B. Relationships between childhood maltreatment, adult health and psychiatric outcomes, and medical utilization. Journal of Clinical Psychiatry. 2004;65(Suppl 12):10-15.

16. Briere J, Woo R, McRae B, Foltz J, Sitzman R. Lifetime victimization history, demographics, and clinical status in female psychiatric emergency room patients. Journal of Nervous and Mental Disease. 1997;185(2):95-101. doi:10.1097/00005053-19970200 $\underline{0-00005}$

17. Wells K. Substance abuse and child maltreatment. Pediatric Clinics of North America. 2009;56(2):345-362. doi:10.1016/i.pcl.2009.01.006

18. Hazlett SB, McCarthy ML, Londner MS, Onyike CU. Epidemiology of adult psychiatric visits to US emergency departments. Acad Emergency Med. 2004;11(2):193-195. doi:10.1111/j.1553-2712.2004.tb 01434.X

19. Pasic J, Russo J, Roy-Byrne P. High Utilizers of Psychiatric Emergency Services. Psychiatric Services. 2005;56(6):678-684. doi:10.1176/appi.ps.56.6.678

20. Burnette ML, Ilgen M, Frayne SM, Lucas E, Mayo J, Weitlauf JC. Violence perpetration and childhood abuse among men and women in substance abuse treatment. Journal of Substance Abuse Treatment. 2008;35(2):217-222. doi:10.1016/i.jsat.2007.10.002

21. Cavaiola AA, Schiff M. Behavioral sequelae of physical and/or sexual abuse in adolescents. Child Abuse \& Neglect. 1988;12(2):181-188. doi:10.1016/01 45-2134(88)90026-9 
22. Dembo R, Williams L, Berry E, et al. The relationship between physical and sexual abuse and illicit drug use: A replication among a new sample of youths entering a juvenile detention center. International Journal of Addiction. 1988;23(11):1101-1123. doi:10.3109/10826088809056 189

23. Mullen PE, Fleming J. Long-term effects of child sexual abuse. Issues in Child Abuse Prevention. (9):1998. Accessed March 19, 2013. http://www.aifs.g

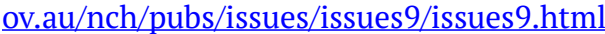

24. Kline DF. Educational and Psychological Problems of Abused Children. Child Abuse \& Neglect. 1977;1(2):301-307. doi:10.1016/0145-2134(77)9000 5-9

25. McNeil DE, Binder RL. Psychiatric Emergency Service Use and Homelessness, Mental Disorder, and Violence. Psychiatric Services. 2005;56(6):699-704. do i:10.1176/appi.ps.56.6.699
26. Modestin J, Wuermle O. Criminality in men with major mental disorder with and without comorbid substance abuse. Psychiatry Clin Neurosci. 2005;59(1):25-29. doi:10.1111/j.1440-1819.2005.0132 7.X

27. Breslow RE, Klinger BI, Erickson BJ. Acute Intoxication and Substance Abuse Among Patients Presenting to a Psychiatric Emergency Service. General Hospital Psychiatry. 1996;18(3):183-219. doi:1 $\underline{0.1016 / 0163-8343(96) 00019-9}$

28. Slagg NB. Characteristics of emergency room patients that predict hospitalization or disposition to alternative treatments. Hospital and Community Psychiatry. 1993;44(3):252-256. doi:10.1176/ps.44.3.2 $\underline{52}$ 